\title{
Study of mandibular foramen from different bony landmarks in dry human mandibles
}

\author{
Shaikh Amjad ${ }^{1}$, Zuberi HR ${ }^{2, *}$, Azhar Ahmed S ${ }^{3}$ \\ ${ }^{1}$ Assistant Professor, Dept. of Dentistry, ${ }^{2}$ Associate Professor, ${ }^{3}$ Professor and HOD, Dept. of Anatomy, JIIUs Indian Institute of \\ Medical Science and Research, Dist. Jalna, Maharashtra, India
}

*Corresponding Author:

Email: zuberihussain@gmail.com

\begin{abstract}
Mandibular foramen is an irregular foramen located just above the center of the medial surface of the ramus of the mandible. Mandibular foramen is leading to mandibular canal through which inferior alveolar nerve and vessels will transmit and supply the teeth of lower jaw. ${ }^{1}$ The inferior alveolar nerve block is the commonest local anesthetic technique which is used for anaesthetizing the lower jaw in various surgical \& dental operations on the mandible and mandibular teeth such as removal of impaction, reductions of fractures and extraction of teeth. The success of this technique highly depends on the proximity of the needle tip to the MF at the time of the anesthetic injection. The aim of the study was to find exact location of mandibular foramen from different anatomical landmark. In present study we took 60 dry human mandibles $\&$ all the distances were measured from center of mandible to different landmark on both sides. The mean of MF-AB distance on right side is $15.6 \mathrm{~mm} \&$ on left side is $15.3 \mathrm{~mm}$. Mean of MF-PB distance are $12.0 \mathrm{~mm} \& 11.0 \mathrm{~mm}$ on right side and left side respectively. MF-MB distance $23.4 \mathrm{~mm}$ and $22.9 \mathrm{~mm}$ are the mean of MF-MN on right and left side respectively. The mean of MF-AG is $23.2 \mathrm{~mm}$ on right side $\& 24.2 \mathrm{~mm}$ on left side. There is great variation found in the position of MF in previous studies. The present study helps in dental anaesthesia and also would help dental surgeons to avoid complications.
\end{abstract}

Keywords: Mandibular foramen, Landmark, Inferior alveolar nerve distance.

\section{Introduction}

Mandibular foramen is an irregular foramen located just above the center of the medial surface of the ramus of the mandible. Mandibular foramen is leading to mandibular canal through which inferior alveolar nerve and vessels will transmit and supply the teeth of lower jaw $^{1}$ Placement of mandibular endosseous implants can be problematic especially in the area of neurovascular bundles. The complications, such as altered sensation, numbness and pain, often occurred if these vital structures, such as inferior alveolar nerve (IAN) and foramen, are not properly identified. In addition, damage of related blood vessels (e.g., inferior alveolar or lingual artery) may lead to excessive bleeding. Damage to these vital structures often arise from clinicians surgical mistakes as well as fails to identify these structures. ${ }^{2}$ Hence, it is critical to determine the location and configuration of the mandibular canal (MC) and related anatomical structures so these types of damages can be minimized. ${ }^{3}$

The MF leads into the mandibular canal (MC), a canal which traverses the body of the mandible. The inferior alveolar nerve block is the commonest local anesthetic technique which is used for anaesthetizing the lower jaw in various surgical \& dental operations on the mandible and mandibular teeth such as removal of impaction, reductions of fractures and extraction of teeth. Unfortunately the failure rate of this technique is high and commonest cause being inaccurate localization of mandibular foramen. ${ }^{4}$ The success of this technique highly depends on the proximity of the needle tip to the MF at the time of the anesthetic injection. ${ }^{5}$ IAN block failure is not uncommon and it occurs even with experienced hands. ${ }^{6-8}$ Failure with this procedure could be as high as $45 \%$.

The aim of this study is to determine the position of the mandibular foramen from various anatomical landmarks in several dry adult human mandibles and provide valuable information to our clinician and dental practitioners.

\section{Materials and Method}

The study was designed and performed in department of Anatomy, JIIUS, IIMSR Warudi, Badnapur. 60 dry human mandibles were selected from the skeletal collection of the department of Anatomy, IIMSR Warudi, Badnapur. All were adult mandibles and the exact ages of which were not known. Only those mandibles were selected which had first or second molars or canine tooth present on the same side.

The edentulous, damaged mandibles and mandibles with tilted occlusal plane of the molars were excluded from the study. The positions of the mandibular foramen from various landmarks were recorded on both the sides of the mandibular ramus, so total 120 measurements were taken from 60 mandibles. The measurements were taken with the help of a compass asthesio meter. For anatomical study of the mandibular foramen, the measurement were taken from the anterior border of the mandibular foramen to the anterior border of the ramus of mandible and designated as (MF-AB) and from the posterior border of the mandibular foramen to the posterior border of the ramus (MF-PB). Similarly, distance from the superior border of the 
mandibular foramen to the mandibular notch (MF-MN), from posterior inferior border mandibular foramen to the angle of mandible (MF-AG) and distance from the superior border of the mandibular foramen to the base of the mandible (MF-MB) were measured and recorded [Fig. 1]. The distances from the mandibular foramen to various landmarks were calculated as a mean of two measurements recorded independently by two people. All the measurements were recorded in millimeters with accuracy of $0.01 \mathrm{~mm}$. The height of ramus was calculated by adding the (MF-MB) and (MF-MN) distances and the horizontal width of ramus was measured from the anterior border of the ramus of mandible to the posterior border of the ramus passing through the middle of the mandibular foramen (AB$\mathrm{PB})$. The width of the mandibular foramen was calculated by subtracting, the sum of the distances of (MF-AB) and (MF-PB) from the distance between anterior border of ramus to the posterior border of ramus of the mandible (AB-PB). The midpoint of horizontal width and vertical height of the ramus was calculated and the position of mandibular foramen with respect to the midpoint of horizontal width and vertical height was calculated.

\section{Results}

The mean distance for each measurement of both sides of the mandible, range and the standard deviation (SD) is tabulated in [Table 1]. Measurements of ramus of mandible and mandibular foramen are summarized in [Table 2]. The mean distance from the mandibular foramen to the anterior border of the ramus was $15.6 \pm$ $1.66 \mathrm{~mm}$ and $15.3 \pm 1.99 \mathrm{~mm}$ on the right and left sides respectively and from the mandibular foramen to the posterior border of the ramus was $12.0 \pm 1.65 \mathrm{~mm}$ and $11.0 \pm 1.82 \mathrm{~mm}$ on the right and left sides respectively. The Mandibular foramen is positioned at a mean distance of $17.70 \pm 2.56 \mathrm{~mm}$ on the right side and 17.0 $\pm 2.17 \mathrm{~mm}$ on the left side, from the mandibular notch. Likewise, the mean distance between superior border of the mandibular foramen and mandibular base is $23.4 \pm$ $3.25 \mathrm{~mm}$ on the right side and $22.9 \pm 3.05 \mathrm{~mm}$ on the left side. The mean distance from mandibular foramen and angle of the mandible was found to be $23.2 \pm 3.80$ $\mathrm{mm}$ on the right side and $24.2 \pm 3.17 \mathrm{~mm}$ on the left side [Table 1].

Table 1: Distances (in $\mathrm{mm}$ ) from the mandibular foramen to various landmarks of the mandible

\begin{tabular}{|l|c|c|c|c|}
\hline Measurements & Side & Range & Mean & $\begin{array}{c}\text { Standard } \\
\text { deviation (SD) }\end{array}$ \\
\hline MF-AB & Right & $12.75-19.18$ & 15.6 & 1.66 \\
\hline & Left & $12.48-19.44$ & 15.3 & 1.99 \\
\hline MF-PB & Right & $09.40-15.60$ & 12.0 & 1.65 \\
\hline & Left & $09.30-15.00$ & 11.0 & 1.82 \\
\hline MF-MN & Right & $13.80-20.14$ & 17.7 & 2.56 \\
\hline & Left & $13.40-21.30$ & 17.0 & 2.17 \\
\hline MF-MB & Right & $15.14-26.60$ & 23.4 & 3.25 \\
\hline & Left & $15.20-25.90$ & 22.9 & 3.50 \\
\hline MF-AG & Right & $13.00-26.60$ & 23.2 & 3.80 \\
\hline & Left & $12.60-27.20$ & 24.2 & 3.17 \\
\hline
\end{tabular}

The average height of the mandibular ramus was found to be $43.15 \pm 5.85 \mathrm{~mm}$ of right side and $42.70 \pm$ $5.78 \mathrm{~mm}$ of left side. Likewise average width of the ramus was found to be $30.23 \pm 2.15 \mathrm{~mm}$ of right side and $30.02 \pm 2.0 \mathrm{~mm}$ of left side.
The diameter (width) of mandibular foramen is calculated by subtracting, the sum of the distances of (MF-AB) and (MF-PB) from the distance between anterior and posterior borders of ramus of the mandible (AB-PB) and its mean was $2.5 \pm 1.0 \mathrm{~mm}$ on right side and $2.2 \pm 0.75 \mathrm{~mm}$ on left side [Table 2].

Table 2: Measurements (in $\mathrm{mm}$ ) of ramus of the mandible and mandibular foramen

\begin{tabular}{|c|c|c|c|c|}
\hline Measurements & Side & Range & Mean & $\begin{array}{c}\text { Standard } \\
\text { deviation (SD) }\end{array}$ \\
\hline Height of ramus & Right & $30.06-54.0$ & 43.15 & 5.85 \\
\hline & Left & $30.0-53.2$ & 42.70 & 5.78 \\
\hline Width of ramus & Right & $25.88-35.4$ & 30.23 & 2.15 \\
\hline & Left & $25.79-35.8$ & 30.02 & 2.05 \\
\hline Diameter of MF & Right & $1.50-4.89$ & 2.5 & 1.00 \\
\hline & Left & $1.75-3.8$ & 2.2 & 0.75 \\
\hline
\end{tabular}




\section{Discussion}

Anatomic variations of the mandible may result in clinical complications if not properly identified, revealing the importance of studying the incidence of these variations 9 . Restoration of form and function without violating important anatomic structures is a fundamental goal in the surgical management of patient. $^{10}$

From an embryological perspective variations of number in the mandibular canal can be explained because in the early development, the inferior alveolar nerve innervate the anterior teeth group, premolar and the molar region in an independent way. ${ }^{11}$ The mandibular accessory foramina were related from its first description with the irrigation and the veined drainage of the temporary teeth's system and of the alveolar processes in formation. From birth, this canal suffers a gradual obliteration during the first year of life. In adults, when these foramina remain, it is considered as an anatomical variation. ${ }^{12}$

Greate variation are found in the position of MF with different landmark. The variability of the position of MF makes it difficult to anaesthetize the inferior alveolar nerve. ${ }^{13,14}$ variations may be due to different age, sex, and difference in the methods used to measure the distance. A study on 34 adult Turkish mandibles showed that the AB- MF was $16.9 \mathrm{~mm}$ and $16.78 \mathrm{~mm}$ on the right and left sides respectively. The PB-MF was found to be $14.09 \mathrm{~mm}$ on the right side and $14.37 \mathrm{~mm}$ on the left side. The MI-MF was $22.37 \mathrm{~mm}$ on the right side and $22.17 \mathrm{~mm}$ on the left side. The of MF- MB is $30.97 \mathrm{~mm}$ on the right side and $29.75 \mathrm{~mm}$ on the left side. ${ }^{15}$ According to the present study, the mean ABMF is $16.31 \pm 2.51 \mathrm{~mm}$ on right side \& $16.33 \pm 2.54 \mathrm{~mm}$ on left side.PB-MF is $14.74 \pm 2.47 \mathrm{~mm} \& 14.64 \pm 2.41 \mathrm{~mm}$ on right \& left side respectively. MN-MF is $22.98 \pm 3.09 \mathrm{~mm} \& 23.06 \pm 3.15$ on right \& left side. AGMF is $26.45 \pm 3.51 \mathrm{~mm}$ on right side and $26.03 \pm 3.62 \mathrm{~mm}$ found on left side. Other variation found compare to present study are given in following chart.

Karthikeya Patil et al. studied 25 Indian dry human adult mandibles and found that average mandibular ramus width was $30.2 \mathrm{~mm} .{ }^{20}$ In our study average mandibular ramus width was found to be $30.23 \pm 2.15$ $\mathrm{mm}$ on the right side and $30.02 \pm 2.0 \mathrm{~mm}$ on the left side which is close to the results of our study.

Table 3: Studies on mandibular foramen by various authors

\begin{tabular}{|l|c|c|c|c|c|}
\hline \multicolumn{1}{|c|}{ Author } & Side & MF-AB & MF-PB & MF-MN & MF-AG \\
\hline $\begin{array}{l}\text { Pranjanaparamitasamanta } \\
(2013)^{16}\end{array}$ & Right & $15.72 \pm 2.92$ & $13.29 \pm 1.74$ & $22.70 \pm 3.0$ & $21.54 \pm 2.92$ \\
\hline & Left & $16.23 \pm 2.88$ & $12.73 \pm 2.04$ & $22.27 \pm 2.92$ & $21.13 \pm 3.43$ \\
\hline Prado et al (2010) ${ }^{17}$ & Right & $19.2 \pm 3.6$ & $14.2 \pm 8.4$ & $23.6 \pm 3.1$ & \\
\hline & Left & $18.8 \pm 3.8$ & $13.0 \pm 2.6$ & $23.1 \pm 3.0$ & \\
\hline $\begin{array}{l}\text { Qudusia Sultana et } \\
\text { al.(2016) }\end{array}$ & Right & $17.69 \pm 2.7$ & $11.39 \pm 1.9$ & $23.87 \pm 4.5$ & $17.9 \pm 3.5$ \\
\hline & Left & $17.94 \pm 2.72$ & $22.39 \pm 3.1$ & $23.66 \pm 4.3$ & $17.6 \pm 3.7$ \\
\hline $\begin{array}{l}\text { Anil Sastya1, } \\
\text { Preeti.(2016) }\end{array}$ & Right & $16.31 \pm 2.51$ & $14.74 \pm 2.47$ & $22.98 \pm 3.09$ & $26.45 \pm 3.51$ \\
\hline & Left & $16.33 \pm 2.54$ & $14.64 \pm 2.41$ & $23.06 \pm 3.15$ & $26.03 \pm 3.62$ \\
\hline Peresnt study & Right & $15.6 \pm 1.66$ & $12.0 \pm 1.65$ & $17.70 \pm 2.56$ & $23 \pm 3.8$ \\
\hline & Left & $15.3 \pm 1.99$ & $11.10 \pm 1.82$ & $17.0 \pm 2.17$ & $24 \pm 3.17$ \\
\hline
\end{tabular}

\section{Conclusion}

Precise localization of mandibular foramen is clinically very important to achieve effective inferior alveolar nerve block, prior to dental surgeries in the lower jaw like osteotomy, orthognathic reconstruction surgeries of the mandible and dental implant procedures ${ }^{21}$ and to avoid injury to the neurovascular contents passing through it. Accessory mandibular foramina will serve as a route for spread of infection and tumor cells. ${ }^{22}$ The present study concludes that the pinpoint knowledge on the position of mandibular foramen with its normality and laterality is important for planning and conducting dental surgeries, which will help for effective management, better result and prognosis. Since some investigators have stated that anaesthesia is essential for both the patients and the dentists, quoting that the opinion of the patients about their dentists was strictly based on their experience with local anaesthesia, it was preferred to infiltrate the anaesthetic solution in close proximity to the MF in the IA nerve block.

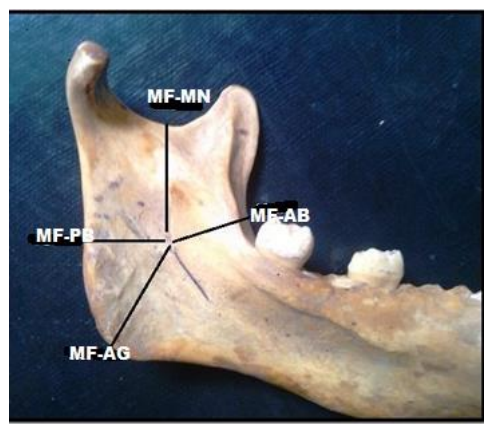

Fig. 1: Measurements of various landmarks from mandibular foramen 
a. Anterior border of the mandibular foramen to the anterior border of the ramus of mandible (MF-AB)

b. Posterior border of the mandibular foramen to the posterior border of the ramus (MF-PB).

c. Superior border of the mandibular foramen to the mandibular notch (MF-MN),

d. Mandibular foramen to the angle of mandible (MFAG)

e. Superior border of the mandibular foramen to the base of the mandible (MF-MB)

\section{References}

1. Standring S. From Gray's Anatomy, The anatomical basis of clinical practice, 40th edition. Churchill livingstone, Elsevier. 20017. Chapter-31;530-3,595-614.

2. Kim IS, Kim SG, Kim YK, Kim JD. Position of the mental foramen in a Korean population: a clinical and radiographic study. Implant Dent 2006;15(4):404-11.

3. Rueda S, Gil JA, Pichery R, Alcañiz M. Automatic segmentation of jaw tissues in CT using active appearance models and semi-automatic landmarking. Med Image Comput Comput Assist Interv 2006;9(Pt 1):167-74. [Medline: 17354887] [doi: 10.1007/11866565_21]

4. Oguz O, Bozkir MG. Evaluation of the location of the mandibular and the mental foramina in dry, young, adult human male, dentulous mandibles. West Indian Med J 2002;51(1):14-6.

5. Palti DG, Almeida CM, Rodrigues AC, Andreo JC, Lima Jeo. An anesthetic technique for the inferior alveolar nerve block: a new approach J Appl Oral Sci 2011;19(1):11-5.

6. Potocnik I. and Bajrovic F. (1999) Failure of inferior alveolar nerve block in endodontics. Endod Dent Traumatol 15:247-25.

7. Vinckier I. (2000) What is the cause of failures of local anaesthesia? Rev. Belge Med Dent 55:41-50.

8. Madan G.A., Madan S.G., Madan A.D. (2002) Failure of inferior alveolar nerve block: exploring the alternatives. $J$ Am Dent Assoc 133:843-6.

9. Priya, R. and Manjunath, KY. Balasubramanyam. Retromolar foramen. Ind J Dent Res 2005;16(1):15-6.

10. AL-Khateeb, T., Hamasa,. and Ababhneh, KT. Position of the mental foramen in a northern regional Jordanian population. Surg Radiol Anat 2007;29:231-7. http://dx.doi.org/10.1007/s00276-007-0199-z

11. Chavez-Lomeli, ME., Mansilla Lory, J., Pompa, JA. and Kjaer, I. The human mandibular canal arises from three separate canals innervating different tooth groups. J Dent Res 1996;75:1540-4. http://dx.doi.org/10.1177/0 0220345960750080401

12. Figun, M. and Garino, R. Anatomía Odontológica Funcional y Aplicada. 2. ed. Buenos Aires: El Ateneo, 2001.

13. Nicholson ML, A study of the position of the mandibular foramen in the adult human mandible. Anat Rec 1985;21:110-112.

14. Afsar A, Haas Da, Rossouw PE, Wood RV, Radiographic localization of mandibular anaesthesia landmarks. Oral Surg Oral Med Oral Radiol Endod 1998;86:234-41.

15. Oguz O, Bozkir MG. Evaluation of the location of the mandibular and the mental foramina in dry, young, adult human male, dentulous mandibles. West Indian Med J 2002;51(1):14-6.
16. Pranjanasamanta marphometric analysis of mandibular foraman and incidence of acessory mandibular foraman in adult human mandibles in indianpopulation. Rev Arg de Anat Clin 2013;5(2):60-6.

17. Prado, F.B., Groppo, F.C., Volpato, M.C. and Caria, P.H.F. Morphological changes in the position of the mandibular foramen in dentate and edentate Brazilian subjects. Clin Anat 2010;23:394-39.

18. Qudusia Sultana et al. Study of surgical landmarks of mandibular foramen for inferior alveolar nerve block: An Osteological study. Ind J Clin Anat Physiol 2016;3(1):3740.

19. Anil Sastya, Preeti. Int J Sci Res 2016;5(10):62-64

20. Karthikeya Patil, Mahima V Guledgud, Preeti Tomar Bhattacharya. Reliability of Panoramic Radiographs in the Localization of Mandibular Foramen. J Clin Diag Res 2015;9(5):ZC35-8.

21. Slootwerg PJ, Muller H. Mandibular invasion by squamous cell carcinoma. Craniomaxillary Surg 1989;17:69-74.

22. Fanibunda K, Matthews JNS. Relationship between accessory foramina and tumor spread in the lateral mandibular surface. J Anat 1999;195:185-190. 